\title{
Softening Competition by Enhancing Entry: An Example from the Banking Industry ${ }^{1}$
}

\author{
Jan Bouckaert ${ }^{2}$ and Hans Degryse ${ }^{3}$
}

July 12,2002

\footnotetext{
${ }^{1}$ We thank participants at the 2002 European Summer Symposium in Financial Markets at Gerzensee. Elena Carletti, Vittoria Cerasi, Thierry Foucault, Roman Inderst, Steven Ongena, and especially Marco Pagano offered useful comments. This paper was written in January 2002 when the second author visited CSEF at the University of Salerno. We thank CSEF for giving us the opportunity to work on this project. We acknowledge the financial support from FWO project G.0302.00 and the TMR-Network on the Industrial Organization of Banking and Financial Markets.

${ }^{2}$ University of Antwerp, Department of Economics, Prinsstraat 13, B-2000 Antwerp, Belgium. Email: jan.bouckaert@ua.ac.be

${ }^{3}$ Katholieke Universiteit Leuven and CentER for Economic Research, Naamsestraat 69, B3000 Leuven, Belgium. Email: hans.degryse@econ.kuleuven.ac.be
} 


\begin{abstract}
We show that competing firms relax overall competition by lowering future barriers to entry. We illustrate our findings in a two-period model with adverse selection where banks strategically commit to disclose borrower information. By doing this, they invite rivals to enter their market. Disclosure of borrower information increases an entrant's second-period profits. This dampens competition for serving the first-period market.

JEL: D43, L13, G21

Keywords: barriers to entry; asymmetric information; switching costs; banking competition.
\end{abstract}




\section{Introduction}

Most oligopoly models of barriers to entry impose a temporal asymmetry between firms. In the simplest framework, one firm enjoys an incumbency position while another takes up the role of the entrant. Prior to potential entry, the incumbent has a monopoly position. Exogenous factors usually explain the temporal asymmetry. The incumbent entered the market early, possibly because of its technological lead. This temporal asymmetry allows the established firm to accumulate a sufficient amount of "capital" in order "to limit the entry of other firms or even to make their entry unprofitable" (Tirole (1988), p.315). In this way, the established firm can optimally take advantage of its incumbency position by creating barriers to entry limiting or even preventing competition.

The importance of dynamic models of oligopoly related to entry barriers and accommodation cannot be overstated. However, often firms compete for incumbency positions. As a result, the exogenous temporal asymmetry between incumbent and entrant is absent. In this paper, we depart from this exogenous asymmetry and focus on the strategic effects when incumbent and entrant status arises endogenously. In a two-period duopoly model, we show that an endogenous temporal asymmetry results in incumbent firms having an incentive to lower future barriers to entry. By lowering barriers, competition between firms for serving the first-period market and taking up the role as incumbent in the second period is seriously reduced. The basic intuition behind this result is that lowering future entry barriers increases an entrant's second-period profits. Firms rationally anticipate that lower future entry barriers generate higher profits from entry. In our model, profitable entry results from sufficiently heterogeneous consumer switching costs and firms' ability to price discriminate between old and new customers. Of course, the incumbent firm must be able to credibly commit to lower future entry barriers. When such commitment is possible, overall competition may drastically decrease as a result of the lower future entry barriers.

We develop our argument within the context of a credit market with adverse selection. Dell'Ariccia et al. (1999) show that in a multi-period model in which incumbents are exogenously given and in which only the incumbent banks know their borrowers' characteristics, it may be hard or even impossible for other banks to enter. In contrast, when banks must compete for an incumbency position, we find that they strategically write a 
binding agreement disclosing information about their borrowers' first-period project outcomes. Such an agreement clearly lowers future barriers to entry and enables rival banks to profitably enter the incumbent's second-period market. Thus, information disclosure rules out entry deterrence or blockaded entry and guarantees profitable entry. Clearly, information disclosure creates second-period competition. However, it relaxes first-period competition for borrowers by more than the increase in second-period competition. The intuition is that banks anticipate profits from entering in the second period even when not serving borrowers in the first period. As a result, banks have less incentives to win first-period competition and to become the incumbent bank in the second period.

Although we develop our analysis for credit markets, our setting yields a much more general insight. When firms compete for new customers, they may strategically commit to lower future entry barriers. By doing this, they invite rivals to enter their future market. Lowering future barriers to entry increases an entrant's second-period profits dampening first-period competition for serving the market. Inviting entry improves the rival's outside option and guarantees future profits to be reaped from the incumbent's market. This relaxes first-period competition as the incumbent firm anticipates its current customers may switch in the future to its rival. For example, when switching costs are sufficiently heterogeneous, it is profit maximizing for employers to allow a rival employer for some future labor poaching. By facilitating future poaching, employers will compete less fiercely today for fresh labor. Facilitation can, for example, take the form of verifiable publication of an employee's professional achievements. ${ }^{1}$

This paper also explains the incentives for borrower information disclosure towards rival banks and its strategic effects on the dynamics of banking competition. Financial market participants put forward that banking competition and financial integration should go hand in hand. In this perspective, the European Commission monitors the process of financial and banking market integration (see e.g. Danthine et al. (2001)). The Riegle-Neal act in the US introducing the possibility of interstate branching also aims to stimulate financial integration. In general, markets are said to be integrated when the law of one price holds. Complementary measures of financial integration are based on "broad market characteristics, " e.g. the cross-border penetration of commercial banks

\footnotetext{
${ }^{1}$ Rønde (2001) investigates the role of information sharing in a labor market context with an exogenous incumbent-entrant set-up.
} 
and other financial institutions (Pagano (2002)). Financial and banking markets are integrated when "sufficient" cross-border entry and cross-border activities occur. We argue that communication of borrower information between banks indeed enhances integration through entry and switching of bank-firm relationships. This, however, comes at the cost of decreased banking competition. Interestingly, financial integration as measured by the possibility to enter each other's market may therefore dampen overall competition in a dynamic context.

Lenders do communicate credit information to each other about businesses and households. This exchange of information can be informal or formal. Jappelli and Pagano (2000) and Kallberg and Udell (2001) provide a detailed overview of the information exchange mechanisms. The communication is informal when one lender contacts another lender to know more about the status of a borrower. Formal exchange of information may be regulated or voluntary. It takes the form of "public credit registers" when regulated and organized by central banks. Voluntary exchange of information occurs through private "credit bureaus" or private information brokers as Dun $\&$ Bradstreet corporation. ${ }^{2}$ Formal exchange of information often takes place even though the size of the partners is highly asymmetric. For example, both large and small banks participate in information exchange agreements. As a consequence, some members benefit more from the information exchange than others. Our paper shows that voluntary information disclosure arises independent of potential reciprocity in receiving information from a rival bank. Thus, banks may spontaneously provide information for strategic reasons as increasing a rival's second-period profits lowers overall competition.

Our model includes some stylized facts of banking competition. Banks enjoy some market power in retail and corporate banking (see Vives (2001)). Sources of market frictions may stem from switching costs in retail banking and established relationships and asymmetric information in corporate banking. Switching costs relax competition once borrowers have established a relation. From an ex-ante point of view, however, banks may compete harshly to establish a relationship with their borrowers. ${ }^{3}$ The resulting "informational" hold up problem in bank-borrower relationships has been analyzed in

\footnotetext{
${ }^{2}$ Kallberg and Udell (2001) investigate the viability and added value of private information brokers. Their empirical work, based on credit data produced by Dun\&Bradstreet, shows that information sharing adds value in solving problems with borrower informational opacity.

${ }^{3}$ Klemperer (1995) provides a nice overview of the implications and importance of switching costs.
} 
dynamic settings (see e.g. Sharpe (1990) and Rajan (1992)). Banks set up customer relationships with their borrowers. The implications are that borrowers pay above actuarially fair interest rates once they are locked-in into a multi-period relationship, as they cannot signal their high quality level to outside banks. These "higher" interest rates are however entirely competed away by "lower" interest rates in the first period of the game. Our paper investigates the interaction between both types of credit market frictions. We show that banks commit to strategies that discipline the informational hold-up problem but add a switching cost lock-in problem. The disciplining of the informational hold-up realizes through committing to provide information about borrowers. This action invites competition by a rival bank when borrowers are old. With sufficient heterogeneity in switching costs among borrowers, it is not optimal for a bank to deter entry and serve all of its high-ability borrowers. Therefore, the informational hold-up problem is replaced by a switching cost hold-up problem. The difference in our model, however, is that the informational hold-up is entirely competed away in the first period whereas this is not the case for switching costs.

Information disclosure or information sharing may severely impact strategic behavior. Although a bank loses part of its informational rents on its local customer base, banks may reduce adverse selection by voluntarily providing information on "migrants" moving from one area to another (Pagano and Jappelli (1993)). In an adverse selection model with exogenously given incumbency, Bouckaert and Degryse $(2001)^{4}$ show that incumbent banks may reduce the scope of entry by strategically disclosing information about defaulters. The current paper shows that when the incumbency and entry status are endogenously determined, information disclosure about all borrowers relaxes competition. Disclosure of information increases profits from entering in the second period. As a result, banks compete less vigorously to win first-period borrowers and to become the incumbent bank in the second period. In a model with moral hazard, Padilla and Pagano (1997, 2000) show that committing to share information may serve as a borrower discipline device. Information sharing increases competition but stimulates entrepreneurial incentives. Our paper also shows that second-period competition increases. In contrast, information disclosure relaxes overall competition: being second-period entrant becomes more attractive. Gehrig and Stenbacka (2001) show that in a model in which entry is

\footnotetext{
${ }^{4}$ A previous version appeared as CEPR Discussion Paper No 2936 and CSEF Discussion Paper $\mathrm{N}^{\circ} 79$.
} 
unprofitable, information sharing relaxes competition. Our results show that competition is softened by inviting entry and increasing the entrant's profitability.

This paper is also related to the literature on switching costs. Typically, this literature assumes homogenous switching costs (for an overview, see Klemperer (1995)). In addition, current market shares of firms are taken as given or it is assumed that one firm has already an incumbency position (Klemperer (1987). Typically, when firms can price discriminate between young and old customers, no equilibrium switching occurs. We depart in two ways from this set up. First, we introduce sufficient heterogeneity in switching costs. When consumers have sufficiently dispersed switching costs, entry may result. Consequently, switching may occur in equilibrium. Second, firms will fight for an incumbency or entrant position.

Our model starts from a homogenous market in the first period and introduces frictions in the second period stemming from switching costs. In our model, equilibrium switching of a fraction of the borrowers takes place when entry occurs. An incumbent prefers to milk its first-period customers with high switching costs to setting a limit price that keeps the entrant out of its market. The incumbent's "entry-inviting" pricing behavior relaxes overall competition. Therefore, our model confirms the result that switching costs lower competition even when taking into account ex-ante competition.

Our set-up is also related to Fudenberg and Tirole (2000). They analyze the issue of customer poaching and brand switching in a two-period Hotelling model. Our results corroborate theirs in that "inviting entry for the marginal first-period customer" may lower first-period competition. In contrast, our model starts from homogeneous goods in the first period and addresses a commitment device that relaxes overall competition.

The remainder of the paper is organized as follows. Section 2 presents the basic model. Sections 3 and 4 develops the first-period and second-period competition analysis. Section 5 offers the main results of our paper by addressing the issue of endogeneous information display. Section 6 discusses the robustness of our set up. Finally, Section 7 concludes.

\section{The Model}

There is a market of mass one in which borrowers are active for two subsequent periods. Borrowers discount the future at rate $0 \leq \delta \leq 1$. In every period, each borrower wants to 
invest in a one-period project requiring one unit of capital. They have no initial wealth but can choose to borrow from bank $i$ with $i=A$ or $B$. Credit applications with several banks within the same period are too costly for borrowers. This assumption prevents borrowers from applying with two banks per period.

Establishing a relationship with a particular bank implies a once and for all specific cost $s$ for every borrower. ${ }^{5}$ We assume that $s \in[\underline{s}, \bar{s}]$ is uniformly distributed among borrowers. In other words, borrowers incur no additional relationship costs when they remain with their first-period bank $i$ in the second period. In contrast, first-period borrowers must duplicate the relationship cost $s$ in the action of switching to another bank $j \neq i$ in the second period. In what follows we restrict the parameters of the model to satisfy the assumptions so that $0 \leq 2 \underline{s}<\bar{s}$. That is, borrowers are sufficiently heterogeneous with respect to switching costs. It allows for entry in period two in a market when asymmetric information is not too harsh. ${ }^{6}$ Moreover, all borrowers have positive switching costs. Borrowers do not know the level of the switching cost $s$ nor their type until after the first period. In other words, they learn their switching cost and their type through undertaking a project. The switching cost of all borrowers is assumed to be constant over time.

Borrowers are risk neutral and have the same expectations about their actual switching costs. Borrowers are of high ability with probability $0<\mu \leq 1$. In this event, borrowers execute projects that succeed with probability 1 and return $q$. We assume that $q$ is large enough so that in equilibrium, when the borrowers' type is known, a bank wants to serve all high-ability credit applicants and every borrower wants to apply for credit. With the remaining probability $1-\mu$, borrowers have low ability and execute projects unsuccessfully with certainty. ${ }^{7}$ Put differently, low-ability borrowers always de-

\footnotetext{
${ }^{5}$ Nilssen (1992) distinguishes between "transaction" and "learning" switching costs. Transaction switching costs are incurred by the consumer at every switch between suppliers. Learning switching costs are incurred only when the consumer switches to a supplier not yet visited. In our model, we have learning switching costs in mind (see Section 5).

${ }^{6}$ This assumption guarantees an equilibrium in pure strategies (see Bester, 1992). In contrast, when $0 \leq \bar{s} \leq 2 \underline{s}$ we could as well assume a constant switching cost $s$ for all borrowers. This alternative assumption would, however, no longer produce entry in the second period as it would always be optimal for the incumbent to deter entry. See Section 6.

${ }^{7}$ Alternatively, low ability borrowers cannot identify successful projects. Or, they never execute a project since they have such a large marginal disutility of effort (see Padilla and Pagano (2000)). Our main results are not qualitatively affected as long as the expected return on low ability borrowers is negative.
} 
fault, are insensitive with respect to the interest rates, and only maximize their private benefits. They apply for credit whenever possible since they enjoy non-pecuniary private benefits $b \geq 0$ (net of expected switching costs) from having access to a credit line. The private benefits are limited such that $b$ is smaller than the bank's cost of attracting one unit of deposits $R_{0}$. That is, low-ability borrowers execute projects with a negative net present (social) value. The proportion of high-ability and low-ability borrowers in the population is common knowledge. The borrowers learn their type (high or low ability and $s$ ) only after having executed a project. Once learned, both types of borrowers always behave according to their type.

Banks compete in loan rates during both periods. Their cost of funding per project equals $R_{0} \geq 1$. Banks also discount the future at rate $0 \leq \delta \leq 1$. They have no information about the borrowers' preferences and characteristics at the beginning of the first period. ${ }^{8}$ As in Sharpe (1990) and von Thadden (2001) we make the following simplifications to concentrate on the role of asymmetric information in credit markets. Each borrower consumes the revenues of his successful projects at the end of every period. ${ }^{9}$ Consequently, every borrower's initial wealth is zero at the beginning of every period. Banks sell one-period contracts and do not offer long-term contracts.

When borrowers are indifferent in the first period between the two banks, we assume that a proportion $0 \leq \sigma \leq 1$ chooses bank $A$. The remaining proportion $1-\sigma$ patronizes bank $B$. This assumption guarantees that when borrowers are indifferent between the two banks in period one, the proportion of the two borrower types is identical in each bank's portfolio. ${ }^{10}$

Every bank enjoys an incumbency advantage in the second period from serving customers on its first-period market. This advantage stems from a bank's private observation whether its borrowers executed a project successfully or not at the end of the first period. This assumption captures the notion of "relationship banking" (Rajan (1992)). Given our assumptions, the observation of project outcomes reveals to the inside bank

\footnotetext{
${ }^{8}$ We assume that borrowers know their own type and switching cost as from period one but rule out that banks observe their borrowers' switching costs.

${ }^{9}$ Alternatively, the remaining output of a successful project cannot be stored (see Padilla and Pagano $(2000))$.

${ }^{10}$ Suppose borrowers would know their type at $t=0$. The assumption that a proportion $\sigma$ of both types would patronize bank $A$ implies that the proportion of the two borrower types is identical in each bank's portfolio.
} 
the borrowers' types: high or low ability. In the remainder of the paper, we will therefore, interchangeably use project outcomes or borrower types. We make the assumption that banks cannot observe borrowers' switching costs.

Prior to first-period competition, every bank makes a binding and enforceable agreement to reveal its private information to its rival bank or not. ${ }^{11}$ Thus, banks commit before competing whether to disclose private information or not. In addition, we assume that if information about project outcomes is publicly disclosed, it is verifiable. This assumption guarantees truthful revelation of information. Given the information disclosure setting committed to at $t=0$, banks compete at $t=1$ for borrowers by setting interest rates. Banks disclose the information as announced at $t=0$ after borrowers have executed their projects. At $t=2$, a bank decides about entering its rival's market and "poaching" the incumbent's first-period borrowers. It can price discriminate between its previous borrowers and new borrowers. ${ }^{12}$

The timing of the game is as follows and its main components are illustrated in Figure 1. Banks decide on information disclosure or not at $t=0$. At $t=1$, they simultaneously decide on interest rates. Borrowers are not aware of their type and relationship cost $s$, choose the bank that maximizes their expected utility, and execute their project. At the end of this period, every bank observes its borrowers' project outcomes and borrowers learn their type and switching cost. At the start of $t=2$, banks disclose information as agreed upon at time 0. Every bank decides whether to enter or not the rival's first-period market. Banks simultaneously set interest rates if entry takes place. Finally, project outcomes are realized.

We solve this game by backward induction. Therefore, Section 3 analyzes banking competition in the second period. We turn to the first period in Section 4. Finally, Section 5 focuses on the equilibrium degree of information disclosure.

\section{Second-period banking competition}

Assume that bank $A$ 's market share from first-period competition equals $k$ and bank $B$ 's $1-k$. Our assumptions ensure an equal fraction of low-ability entrepreneurs in both

\footnotetext{
${ }^{11} \mathrm{An}$ alternative is to provide the borrower with a certificate revealing his project outcome.

${ }^{12}$ It can be shown that a bank optimally does so, since borrowers are sufficiently heterogeneous with regard to switching costs when patronizing another bank.
} 


\begin{tabular}{|c|c|c|c|c|c|c|}
\hline$t=1$ & $\begin{array}{l}\text { Banks } \\
\text { simultaneously } \\
\text { set interest rates }\end{array}$ & $\begin{array}{l}\text { Borrowers } \\
\text { learn } \\
\text { their type }\end{array}$ & $t=2$ & $\begin{array}{l}\text { Banks } \\
\text { about } \\
\text { each c }\end{array}$ & $\begin{array}{l}\text { cide } \\
\text { ering } \\
\text { r's market }\end{array}$ & $\begin{array}{l}\text { Borrowers } \\
\text { choose bank } \\
\text { and execute } \\
\text { project } \\
\end{array}$ \\
\hline $\begin{array}{l}\text { Banks simultaneously } \\
\text { decide about } \\
\text { information display }\end{array}$ & $\begin{array}{l}\text { Borrowers } \\
\text { choose bank } \\
\text { and execute } \\
\text { project }\end{array}$ & $\begin{array}{l}\text { Incumbent bank } \\
\text { learns project } \\
\text { outcomes and } \\
\text { borrowers } \\
\text { learn their type }\end{array}$ & $\begin{array}{l}\text { Banks } \\
\text { inform } \\
\text { or not }\end{array}$ & $\begin{array}{l}\text { lisplay } \\
\text { ation }\end{array}$ & $\begin{array}{l}\text { Banks sim } \\
\text { set interes } \\
\text { market }\end{array}$ & $\begin{array}{l}\text { taneously } \\
\text { ates in each }\end{array}$ \\
\hline
\end{tabular}

Figure 1: The timing of the game.

first-period markets. Consequently, market share $k$ or $1-k$ does not determine the entry decision. Moreover, at the end of $t=1$, borrowers know their type and switching cost. For convenience, we will analyze the market from $A$ 's point of view and assume that $k=1$. In other words, bank $A$ is the incumbent bank $(I)$ and bank $B$ the entering bank $(E)$. Multiplying the profits by $k$ and $1-k$ respectively and adapting the incumbency $(I)$ and entrant $(E)$ status provides us with total second-period profits given first-period market shares. In sum, we only need to make a distinction between information disclosure or not.

\subsection{Information disclosure}

\subsubsection{Demand Analysis}

low-ability borrowers in I's first-period market will not obtain a loan as their type is revealed to both banks. Bank $E$ however can induce bank I's high-ability borrowers to switch by providing lower interest rates than bank $I$. A high-ability borrower in the second period is indifferent between continuing her relationship at bank $I$ and switching relationship to bank $B$ if her switching cost $s^{*}$ is such that

$$
R_{d}^{2 I}=R_{d}^{2 E}+s^{*}
$$

The superscript 2 refers to the second period and the subscript $d$ to information disclosure. Borrowers with a switching cost exceeding $s^{*}$ continue their relationship with bank $A$. In contrast, borrowers with a switching cost lower than $s^{*}$ patronize bank $E$. Bank I's market share $a$ of high-ability borrowers then is defined as 


$$
a \equiv \frac{\bar{s}-s^{*}}{\bar{s}-\underline{s}}
$$

or

$$
a \equiv \frac{\bar{s}-R_{d}^{2 I}+R_{d}^{2 E}}{\bar{s}-\underline{s}} .
$$

Bank A's second-period demand curve of high-ability borrowers can now be defined as

$$
D_{I}\left(R_{d}^{2 I}, R_{d}^{2 E}\right) \equiv \begin{cases}0 & \text { if } R_{d}^{2 E}+\bar{s}<R_{d}^{2 I} \\ \mu a & \text { if } R_{d}^{2 E}+\underline{s} \leq R_{d}^{2 I} \leq R_{d}^{2 E}+\bar{s} \\ \mu & \text { otherwise. }\end{cases}
$$

The first part of Eq. (1) shows that for high enough $R_{d}^{2 I}, I$ does not keep any of its first-period high-ability borrowers. Part two reveals that for intermediate values of bank I's interest rate, some of the high-ability borrowers switch bank whereas others continue their relationship in the second period. Finally, part three presents that when $R_{d}^{2 I}$ is sufficiently low, bank $E$ does not poach high-ability borrowers.

\subsubsection{Best-response analysis}

Bank I's second-period incumbency profit reads as

$$
\Pi_{d}^{2 I}\left(R_{d}^{2 I}, R_{d}^{2 E}\right) \equiv D_{I}\left[R_{d}^{2 I}-R_{0}\right]
$$

where $D_{I} \equiv D_{I}\left(R_{d}^{2 I}, R_{d}^{2 E}\right)$. Similarly, bank E's profit from poaching bank I's first-period customers becomes

$$
\Pi_{d}^{2 E}\left(R_{d}^{2 E}, R_{d}^{2 I}\right) \equiv\left(\mu-D_{I}\right)\left[R_{d}^{2 E}-R_{0}\right]
$$

Banks simultaneously set their interest rates. Accordingly, bank I's best-response looks like

$$
R_{d}^{2 I}= \begin{cases}R_{0} & \text { if } R_{0}-\bar{s}>R_{d}^{2 E} \\ \left(R_{0}+\bar{s}+R_{d}^{2 E}\right) / 2 & \text { if } R_{0}-\bar{s} \leq R_{d}^{2 E} \leq R_{0}+\bar{s}-2 \underline{s} \\ R_{d}^{2 E}+\underline{s} & \text { otherwise. }\end{cases}
$$

Similarly, bank E's best-response function equals

$$
R_{d}^{2 E}= \begin{cases}R_{0} & \text { if } R_{0}+\underline{s}>R_{d}^{2 I} \\ \left(R_{0}-\underline{s}+R_{d}^{2 I}\right) / 2 & \text { if } R_{0}+\underline{s} \leq R_{d}^{2 I} \leq R_{0}+2 \bar{s}-\underline{s} \\ R_{d}^{2 I}-\bar{s} & \text { otherwise. }\end{cases}
$$


Substitution of Eqs. (4) and (5) into Eqs. (2) and (3) yield the following unique profit maximizing solution

$$
R_{d}^{2 I}=\frac{3 R_{0}+2 \bar{s}-\underline{s}}{3} ; R_{d}^{2 E}=\frac{3 R_{0}+\bar{s}-2 \underline{s}}{3}
$$

Bank I's and E's demand equal

$$
D_{I}=\frac{\mu(2 \bar{s}-\underline{s})}{3(\bar{s}-\underline{s})} ; D_{E}=\frac{\mu(\bar{s}-2 \underline{s})}{3(\bar{s}-\underline{s})},
$$

respectively. Their profits then become

$$
\Pi_{d}^{2 I}=\frac{\mu(2 \bar{s}-\underline{s})^{2}}{9(\bar{s}-\underline{s})} ; \Pi_{d}^{2 E}=\frac{\mu(\bar{s}-2 \underline{s})^{2}}{9(\bar{s}-\underline{s})} .
$$

Notice that our assumption $2 \underline{s}<\bar{s}$ ensures that both banks enjoy a positive market share and are able to set an interest rate above the actuarially fair interest rate $R_{0}$. Therefore, with information disclosure entry always occurs. The intuition for this result is as follows. The entering bank is able to deny credit to low-ability entrepreneurs since information is disclosed. Moreover, profitable entry takes place as the incumbent bank refrains from pricing too aggressively: some borrowers have a high second-period preference for the incumbent bank due to their relatively high switching costs.

\subsection{No Information disclosure}

With no information disclosure, we have to distinguish the case in which bank $E$ committed to enter bank I's market or not. Recall that the entry decision does not hinge on market share $k$ since the quality of the pool of borrowers in both first-period markets is identical. Moreover, the entry decision takes place before interest rates are set. Without loss of generality, we assume again that bank $I$ attracted the entire market in the first period.

The analysis with entry is similar to the information disclosure setting except that bank $B$ 's profits now suffer losses from low-ability borrowers. In particular,

$$
R_{n}^{2 I}=\frac{3 R_{0}+2 \bar{s}-\underline{s}}{3} ; R_{n}^{2 E}=\frac{3 R_{0}+\bar{s}-2 \underline{s}}{3}
$$

and 


$$
\Pi_{n}^{2 I}=\frac{\mu(2 \bar{s}-\underline{s})^{2}}{9(\bar{s}-\underline{s})} ; \Pi_{n}^{2 E}=\frac{\mu(\bar{s}-2 \underline{s})^{2}}{9(\bar{s}-\underline{s})}-(1-\mu) R_{0}
$$

where the subscript $n$ stands for no information disclosure. Absence of information disclosure with entry implies that low-ability borrowers are able to obtain a loan at the entering bank. This can readily be seen from the second component of $\Pi_{n}^{2 E}$. Bank $E$ only enters when adverse selection is not too harsh. This happens if $\mu \geq \mu^{*}$, with

$$
\mu^{*} \equiv \frac{9 R_{0}(\bar{s}-\underline{s})}{9 R_{0}(\bar{s}-\underline{s})+(\bar{s}-2 \underline{s})^{2}} .
$$

The fraction $\mu^{*}$ follows from $\Pi_{n}^{2 E}=0$.

Absent entry, bank $I$ obtains a monopoly and charges $q$. Bank I's second-period profits then become $\mu\left(q-R_{0}\right)$ whereas $E$ obtains no profits.

Thus, second-period entry happens when adverse selection is not too harsh $\mu \geq \mu^{*}$. Otherwise bank $E$ does not enter, leaving bank $I$ a monopoly.

\section{First-period Banking Competition}

In this section, we characterize the outcome of the banking competition subgame under alternative information disclosure situations. We endogenize the information disclosure choice in the next section. Three possible cases have to be distinguished. The first is where both banks disclose information. The second is where both banks decided not to disclose information about project outcomes. Finally, only one bank, say bank $A$, discloses information. We call this "asymmetric" disclosure of information decision.

\subsection{Interest rates with information disclosure}

With information disclosure, banks correctly anticipate entry into each other's first-period market. They can price discriminate between "old" borrowers remaining with their firstperiod bank and "new" borrowers in their entering market. This difference in interest rates is only driven by switching costs and not by informational differences between banks about borrowers. As shown in the previous section, the incumbent bank enjoys some market power over its first-period borrowers as they face switching costs in the action of visiting another bank. Thus, there is a hold-up problem in the second period 
stemming from switching costs and not from informational asymmetries. This subsection analyzes how this hold-up problem impacts on competition in the first period.

Denote by $k$ and $1-k$ the market share bank $A$ and $B$ obtain in the first period, respectively. Bank $A$ 's second-period profits then become

$$
\Pi_{A d}^{2} \equiv k \Pi_{d}^{2 I}+(1-k) \Pi_{d}^{2 E}
$$

where the subscript $d$ refers to disclose of information. The total profit for bank $A$ as a function of its first-period interest rate $R_{A d}^{1}$ and the competitor's interest rate $R_{B d}^{1}$ becomes

$$
\Pi_{A d}= \begin{cases}\delta \Pi_{d}^{2 I}+\left(\mu R_{A d}^{1}-R_{0}\right) & \text { if } R_{A d}^{1}<R_{B d}^{1} \\ \delta\left(\sigma \Pi_{d}^{2 I}+(1-\sigma) \Pi_{d}^{2 E}\right)+\sigma\left(\mu R_{A d}^{1}-R_{0}\right) & \text { if } R_{A d}^{1}=R_{B d}^{1} \\ \delta \Pi_{d}^{2 E} & \text { otherwise. }\end{cases}
$$

The first part of Eq. (12) applies when bank $A$ sets a lower rate than its rival. Then it attracts the entire first-period market and is the incumbent in the second period. Part two applies when both banks announce the same interest rate. A fraction $\sigma$ borrows from bank $A$. Therefore, bank $A$ wins for that fraction $\sigma$ first-period competition and is the incumbent bank in the second period. For the complement $1-\sigma$, bank $A$ is entrant in he second period. Finally, part three presents the profits of losing first-period competition and being entrant in the second period. This happens when bank $A$ announces a higher first-period interest rate than its rival. A pure strategy equilibrium in which borrowers are indifferent in the first period will imply that $k=\sigma$. The results for the first-period competition with information disclosure are summarized in Proposition 1.

Proposition 1 With information disclosure, there is a unique Nash-equilibrium in periodone interest rates with

$$
R_{A d}^{1}=R_{B d}^{1}=\frac{R_{0}}{\mu}-\frac{\delta(\bar{s}+\underline{s})}{3}
$$

Total profits become

$$
\Pi_{A d}=\Pi_{B d}=\delta \Pi_{d}^{2 E}
$$

$\mathbf{P}$ roof. Suppose a bank charges a higher first-period interest rate than its rival. Then, it attracts no borrowers in the first period and becomes the entrant in the second period. In this event, its discounted total profits equal $\delta \Pi_{d}^{2 E}$. From Eq. (8) a bank 
prefers to be the incumbent as this yields second-period profits $\Pi_{d}^{2 I}>\Pi_{d}^{2 E}$. Therefore, a bank is willing to undercut its rival even below $R_{0}$. Perfect competition in the first period ensures that the difference between the incumbent's and entrant's profits are competed away such that future gains are traded for current first-period losses. Since $\delta\left(\Pi_{d}^{2 I}-\Pi_{d}^{2 E}\right)=\mu \delta(\bar{s}+\underline{s}) / 3$, the candidate equilibrium first-period interest rates

$$
R_{A d}^{1}=R_{B d}^{1}=\frac{R_{0}}{\mu}-\frac{\delta(\bar{s}+\underline{s})}{3}
$$

imply a first-period profit of $\sigma\left(\mu\left[R_{0} / \mu-\delta(\bar{s}+\underline{s}) / 3\right]-R_{0}\right)$ and a second-period profit of $\delta\left[\sigma \Pi_{d}^{2 I}+(1-\sigma) \Pi_{d}^{2 E}\right]$ for bank $A$. Adding up both profits yields an overall discounted profit equal to $\delta \Pi_{d}^{2 E}$ for both banks. Let us analyze bank $A$ 's first-period price setting behavior given $R_{B d}^{1}=R_{0} / \mu-\delta(\bar{s}+\underline{s}) / 3$. Suppose bank $A$ decides to decrease its interest rate with $\varepsilon>0$ below $R_{B d}^{1}$. Then $A$ attracts the entire market in the first period and becomes the only incumbent in the second period. Its total profits now equal $-\delta(\mu(\bar{s}+\underline{s}) / 3)-\epsilon \mu+\delta \Pi_{d}^{2 I}<\delta \Pi_{d}^{2 E}$. Suppose bank $A$ decides to set a higher interest rate than its rival bank $B$. This implies that bank $A$ attracts no borrowers in the first period. It therefore becomes the entrant in the second period and its total profits become $\delta \Pi_{d}^{2 E}$. Therefore, bank $A$ 's profits do not strictly increase by increasing its interest rate. A similar analysis applies for bank $B$. Any other combination of interest rates will lead to profitable deviation for one or the other bank. This completes the proof of the proposition.

In conclusion, with information disclosure, banks incur first-period losses on their customer base. The losses on these borrowers are equal to the discounted difference between being an incumbent or entrant in the second period. Formally, banks' firstperiod losses equal

$$
\Pi_{A d}^{1}=-\sigma \delta\left(\frac{\mu(\bar{s}+\underline{s})}{3}\right) \text { and } \Pi_{B d}^{1}=-(1-\sigma) \delta\left(\frac{\mu(\bar{s}+\underline{s})}{3}\right) .
$$

The first-period equilibrium interest rates are below the actuarially fair rates $R_{0} / \mu$. This result has to be entirely attributed to the switching cost hold-up problem and not to informational differences. The losses on first-period borrowers are recouped from additional profits in the second period: the switching cost hold-up allows an incumbent to charge a higher interest rate compared to an entrant. Thus, competition for serving the market in the first period ensures that the expected difference in hold-up rents are given back 
upfront to the borrowers. Remark that banks do not compete all rents away over the two periods. The presence of information makes second-period entry profitable independent of the degree of asymmetric information. This relaxes overall competition. Furthermore, a bank can avoid low-ability borrowers by not pricing too aggressively in the first period: letting the rival bank win first-period competition reveals the low-ability types. Since we assumed that the proportion of the two borrower types is identical in each bank's portfolio, our results are independent of $\sigma$. Finally, there is "rent equalization" in that both banks enjoy identical profits.

\subsection{Interest rates without information disclosure}

Banks only enter each other's first-period market when $\mu \geq \mu^{*}$. Otherwise, banks obtain a monopoly in the second period.

\subsubsection{With second-period entry: $\mu \geq \mu^{*}$}

Denote by $k(1-k)$ the market share that bank $A(B)$ obtained in the first period. Bank $A$ 's second period profits then become

$$
\Pi_{A n}^{2}=k \Pi_{n}^{2 I}+(1-k) \Pi_{n}^{2 E}
$$

where the subscript $n$ refers to no information.

The total profit for bank $A$ as a function of its first-period interest rate $R_{A n}^{1}$ and the competitor's interest rate $R_{B n}^{1}$ becomes

$$
\Pi_{A n}= \begin{cases}\delta \Pi_{n}^{2 I}+\left(\mu R_{A n}^{1}-R_{0}\right) & \text { if } R_{A n}^{1}<R_{B n}^{1} \\ \delta\left(\sigma \Pi_{n}^{2 I}+(1-\sigma) \Pi_{n}^{2 E}\right)+\sigma\left(\mu R_{A n}^{1}-R_{0}\right) & \text { if } R_{A n}^{1}=R_{B n}^{1} \\ \delta \Pi_{n}^{2 E} & \text { otherwise. }\end{cases}
$$

A pure strategy equilibrium in which borrowers are indifferent in the first period will imply that $k=\sigma$. The results for the first-period competition with information disclosure are summarized in Proposition 2.

Proposition 2 Without information disclosure and with second-period entry $\left(\mu \geq \mu^{*}\right)$, there is a unique Nash-equilibrium in period one interest rates with

$$
R_{A n}^{1}=R_{B n}^{1}=\frac{R_{0}}{\mu}-\frac{\delta(\bar{s}+\underline{s})}{3}-\frac{\delta(1-\mu) R_{0}}{\mu} .
$$


Total profits become

$$
\Pi_{A n}=\Pi_{B n}=\delta \Pi_{n}^{2 E}
$$

$\mathbf{P}$ roof. Suppose a bank charges a higher first-period interest rate than its rival. Then, it attracts no borrowers in the first period and becomes the entrant in the second period. In this event, its discounted total profits equal $\delta \Pi_{n}^{2 E}$. From Eq. (10) a bank prefers to be the incumbent as this yields second-period profits $\Pi_{n}^{2 I}>\Pi_{n}^{2 E}$. Therefore, a bank is willing to undercut its rival. Perfect competition in the first period ensures that the difference between the incumbent's and entrant's profits are competed away such that future gains are traded for current first-period losses. Since $\delta\left(\Pi_{n}^{2 I}-\Pi_{n}^{2 E}\right)=\delta\left[\mu(\bar{s}+\underline{s}) / 3+(1-\mu) R_{0}\right]$, the candidate equilibrium first-period interest rates are

$$
R_{A n}^{1}=R_{B n}^{1}=\frac{R_{0}}{\mu}-\frac{\delta(\bar{s}+\underline{s})}{3}-\frac{\delta(1-\mu) R_{0}}{\mu}
$$

imply a first-period profit of $\sigma\left(\mu\left[R_{0} / \mu-\delta((\bar{s}+\underline{s}) / 3]+(1-\mu) R_{0} / \mu\right]-R_{0}\right)$ and a secondperiod profit of $\delta\left[\sigma \Pi_{n}^{2 I}+(1-\sigma) \Pi_{n}^{2 E}\right]$ for bank $A$. Adding up both profits yields an overall discounted profit equal to $\delta \Pi_{n}^{2 E}$ for both banks. Let us analyze bank $A$ 's first-period price setting behavior given $R_{B n}^{1}=R_{0} / \mu-\delta(\bar{s}+\underline{s}) / 3-\delta(1-\mu) R_{0} / \mu$. Suppose bank $A$ decides to decrease its interest rate by $\varepsilon>0$ below $R_{B n}^{1}$. Then $A$ attracts the entire market in the first period and becomes the only incumbent in the second period. Its total profits now equal $-\delta\left(\mu(\bar{s}+\underline{s}) / 3+(1-\mu) R_{0}\right)-\epsilon \mu+\delta \Pi_{n}^{2 I}<\delta \Pi_{n}^{2 E}$. Suppose bank $A$ charges an interest rate exceeding $R_{B n}^{1}$. Consequently, bank $A$ attracts no borrowers in the first period. It therefore becomes the entrant in the second period and its total discounted profits become $\delta \Pi_{n}^{2 E}$. Therefore, bank $A$ 's profits do not increase by charging the higher interest rate. A similar analysis applies for bank $B$. Any other combination of interest rates will lead to profitable deviation for one or the other bank. This completes the proof of the proposition.

Proposition 2 shows that first-period loan rates are far below the actuarially fair rates. This result stems from both informational differences and switching costs. Again, without information disclosure and with second-period entry, banks prefer to be incumbent in the second period to entrant. The intuition is even stronger than in the case with information disclosure. This can be seen from comparing Eqs. (8) and (10). In other words, secondperiod entry is not such an attractive option anymore: banks cannot single out unknown 
low-ability borrowers in the second period. Being incumbent is the only way to ensure large profits in the second period. Consequently, first-period competition is relatively harsh and overall profits are lower compared to information disclosure. The first-period equilibrium implies first-period losses equal to

$$
\Pi_{A n}^{1}=-\sigma \delta\left(\frac{\mu(\bar{s}+\underline{s})}{3}+(1-\mu) R_{0}\right) \text { and } \Pi_{B n}^{1}=-(1-\sigma) \delta\left(\frac{\mu(\bar{s}+\underline{s})}{3}+(1-\mu) R_{0}\right) .
$$

Thus, the absence of information harshens competition over the two periods since secondperiod entry is less attractive. high-ability borrowers benefit from the absence of information disclosure as overall competition is harsh. low-ability borrowers benefit as well since an entering bank cannot distinguish borrowers' types. As in Proposition 1, our results are independent of $\sigma$ since the proportion of the two borrower types is identical in each bank's portfolio. Similarly, "rent equalization" follows as both banks enjoy identical profits.

\subsubsection{Without second-period entry: $\mu<\mu^{*}$}

No entry takes place in the absence of information and when adverse selection is too harsh $\left(\mu<\mu^{*}\right)$. Then a bank obtains a monopoly on its first-period customers. However, a bank only benefits from this monopoly situation when it attracts borrowers in the first period. In other words, following the strategy of not attracting customers in the first period leaves you with zero profits in the second period. Second-period profits when incumbent $(k=1)$ in the first period become

$$
\Pi_{n}^{2 I}=\mu\left[q-R_{0}\right]
$$

Otherwise, second-period profits are zero. The total profit for bank $A$ as a function of its first-period interest rate $R_{A n}^{1}$ and the competitor's interest rate $R_{B n}^{1}$ becomes

$$
\Pi_{A n}= \begin{cases}\delta \Pi_{n}^{2 I}+\left(\mu R_{A n}^{1}-R_{0}\right) & \text { if } R_{A n}^{1}<R_{B n}^{1} \\ \delta\left(\sigma \Pi_{n}^{2 I}\right)+\sigma\left(\mu R_{A n}^{1}-R_{0}\right) & \text { if } R_{A n}^{1}=R_{B n}^{1} \\ 0 & \text { otherwise. }\end{cases}
$$

A pure strategy equilibrium in which borrowers are indifferent in the first period will imply that $k=\sigma$. The results for the first-period competition with information disclosure 
are summarized in Proposition 3.

Proposition 3 Without information display and absent second-period entry $\left(\mu<\mu^{*}\right)$, there is a unique Nash-equilibrium in period one interest rates with

$$
R_{A n}^{1}=R_{B n}^{1}=\frac{R_{0}}{\mu}-\delta\left(q-R_{0}\right) .
$$

Total profits become

$$
\Pi_{A n}=\Pi_{B n}=0 .
$$

$\mathbf{P}$ roof. The proof is similar to Propositions 1 and 2.

First period interest rates are far below the actuarially fair rates $R_{0} / \mu$. This result is entirely driven by informational lock-in. Without second-period entry, only the incumbent bank realizes profits in the second period. Therefore, a bank has hughe incentives to win first-period competition. Consequently, first-period competition is harsh and banks offer a serious discount to borrowers in the first period anticipating that borrowers will be informationally locked-in tomorrow. Overall profits are equal to zero. high-ability borrowers pay high interest rates in the second period: they are informationally lockedin. Ex ante however, the informational lock-in problem is unimportant. The intuition is that the informational lock-in is competed entirely away in the first period. This shows up since overall profits are equal to zero. The switching cost hold-up problem is absent since no entry takes place.

\subsection{Interest rates with "asymmetric" disclosure of information decision}

In this subgame we discuss the case in which only one bank discloses information. For convenience suppose only bank $A$ discloses information. We distinguish between two cases where bank $A$ enters $B$ 's market $\left(\mu \geq \mu^{*}\right)$ and where there is no entry $\left(\mu<\mu^{*}\right)$. Since bank $A$ discloses information, bank $B$ will always enter $A$ 's market.

\subsubsection{With entry into the market without information}

Borrowers correctly anticipate second-period interest rates as well as entry by $A$ into $B$ 's market. A borrower is indifferent between borrowing at $A$ and $B$ at $t=1$ if 


$$
\mu R_{A}^{1}=\mu R_{B}^{1}-\delta(1-\mu) b
$$

Thus, borrowers have an extra willingness to pay for bank $B$ not disclosing information. The intuition is when bank $A$ enters $B$ 's market, it will grant low-ability borrowers a loan in the second period. In other words, since $A$ enters $B$ 's market, choosing the bank not disclosing information ensures borrowers access to their private benefits if they turn out to be a low-ability type. Expected switching costs do not influence the marginal borrower as entry is expected to take place in both first-period markets.

The next Proposition presents the main insights.

Proposition 4 When only bank A commits to display information and second-period entry takes place in both markets $\left(\mu \geq \mu^{*}\right)$, there is a unique Nash-equilibrium in periodone interest rates with

$$
\begin{aligned}
& R_{A}^{1}=\frac{R_{0}}{\mu}-\frac{\delta(\bar{s}+\underline{s})}{3}-\frac{\delta(1-\mu) b}{\mu}-\varepsilon \\
& R_{B}^{1}=\frac{R_{0}}{\mu}-\frac{\delta(\bar{s}+\underline{s})}{3} .
\end{aligned}
$$

Bank $A$ attracts all first-period borrowers $(k=1)$. Banks' total profits become

$$
\begin{aligned}
\Pi_{A} & =\delta \Pi_{d}^{2 E}-\delta(1-\mu) b>\delta \Pi_{n}^{2 E} \\
\Pi_{B} & =\delta \Pi_{d}^{2 E}
\end{aligned}
$$

$\mathbf{P}$ roof. From Eq. (8) the discounted difference in profitability between being incumbent and entrant in the second period for bank $B$ equals $(\bar{s}+\underline{s}) / 3$ per highability borrower. Therefore, bank $B$ 's first-period interest rate will not be lower than $R_{0} / \mu-\delta(\bar{s}+\underline{s}) / 3$. Otherwise, bank $B$ can better price such that $A$ obtains the firstperiod market. Similarly, from Eq. (10) bank $A$ will not price lower than $R_{0} / \mu-$ $\delta(\bar{s}+\underline{s}) / 3-\delta(1-\mu) R_{0} / \mu$. Otherwise, bank $A$ is better off being entrant in the second period. Since $b<R_{0}$ implies that borrowers' extra willingness to pay for bank $B$ is smaller than its cost of funding. Therefore bank $A$ does not need to price too aggressively to keep bank $B$ out of its first-period market. Let us analyze bank $A$ 's price setting behavior given $R_{B}^{1}=R_{0} / \mu-\delta(\bar{s}+\underline{s}) / 3$. Bank $A$ has no incentive to set its interest rate below $R_{A}^{1}=R_{0} / \mu-\delta(\bar{s}+\underline{s}) / 3-\delta(1-b) / \mu-\varepsilon$. Given $R_{B}^{1}$, this is the highest interest 
rate at which bank $A$ attracts the entire first-period market. An increase in its interest rate implies leaving (part of) the first-period market to $B$. This action again lowers $A$ 's profits. Bank $B$ has no incentives to lower its interest rate below $R_{B}^{1}=R_{0} / \mu-\delta(\bar{s}+\underline{s}) / 3$ given $R_{A}^{1}=R_{0} / \mu-\delta(\bar{s}+\underline{s}) / 3-\delta(1-\mu) b / \mu-\varepsilon$. Increasing its interest rate does not affect $B$ 's profits. Any other combination of interest rates leads to profitable deviation by one or the other bank. Total bank profits become

$$
\begin{aligned}
& \Pi_{A}=\delta \Pi_{d}^{2 E}-\delta(1-\mu) b>\delta \Pi_{n}^{2 E} \\
& \Pi_{B}=\delta \Pi_{d}^{2 E} .
\end{aligned}
$$

This completes the proof of the proposition.

Bank $B$ attracts no first-period borrowers although they have a higher first-period willingness to pay. However, the extra willingness to pay for a bank not disclosing information is lower than the cost of funds as $b<R_{0}$. The intuition is that bank $A$ is better of undercutting bank $B$ in the first-period since the private benefits are relatively low. This implies that $A$ becomes the incumbent and enjoys the incumbency profits in the second period. Thus, information for the entire market is disclosed at the end of the first period although one of the banks commits not to disclose information.

\subsubsection{No entry into the market without information}

Borrowers correctly anticipate second-period interest rates as well as no entry by $A$ into $B$ 's market. They are indifferent between borrowing at $A$ and $B$ at time 1 if

$$
\mu R_{A}^{1}+\delta \mu\left(\alpha R_{A}^{2 I}+(1-\alpha)\left(R_{B}^{2 E}+E\left(s \mid s<s^{*}\right)\right)=\mu R_{B}^{1}+\delta \mu q\right.
$$

with $\alpha \equiv\left(\bar{s}-s^{*}\right) /(\bar{s}-\underline{s})$ the probability with which a borrower will have a switching cost $s \geq s^{*}$. The first term in the left-hand side of Eq. (33) shows the expected first-period cost of borrowing from bank $A$. The second term reflects the discounted expected cost in the second period. In the event the borrower has high switching costs $s^{*} \leq s$, he will continue borrowing from his first-period bank $A$. In the event the borrower has a low switching cost $s<s^{*}$, he will actually switch to bank $B$. The right-hand side shows the expected cost of borrowing from bank $B$ in the both periods. It clearly illustrates the "bargain-then-ripoff" pricing pattern of bank $B$. 
Thus, borrowers have an extra willingness to pay for the bank disclosing information. The intuition comes in two steps. First, low-ability borrowers do not have access to a loan whatever the choice of bank since no entry is expected in the market absent information. Second, entry is expected in $A$ 's first-period market whereas borrowers are locked in when choosing for $B$. The reason is that $A$ discloses information and $A$ does not enter $B$ 's first-period market.

Proposition 5 When only bank A commits to display information and no second-period entry takes place in the market absent information $\left(\mu<\mu^{*}\right)$, there is a unique Nashequilibrium in period-one interest rates with

$$
\begin{aligned}
& R_{A}^{1}=\frac{R_{0}}{\mu}-\delta\left[\alpha \frac{(\bar{s}+\underline{s})}{3}+(1-\alpha) E\left(s \mid s<s^{*}\right)\right]-\varepsilon \\
& R_{B}^{1}=\frac{R_{0}}{\mu}-\delta\left[q-R_{0}\right]+\delta \frac{(\bar{s}-2 \underline{s})^{2}}{9(\bar{s}-\underline{s})} .
\end{aligned}
$$

Bank $A$ attracts all first-period borrowers $(k=1)$. The equilibrium profits become

$$
\begin{aligned}
\Pi_{A} & =\frac{\delta \mu(\bar{s}-2 \underline{s})^{2}}{6(\bar{s}-\underline{s})} \\
\Pi_{B} & =\delta \Pi_{d}^{2 E} .
\end{aligned}
$$

$\mathbf{P}$ roof. Bank $B$ will not price lower than $R_{0} / \mu-\delta\left[q-R_{0}\right]+\delta(\bar{s}-2 \underline{s})^{2} / 9(\bar{s}-\underline{s})$. The reason is that by becoming incumbent the additional profits he makes compared to being entrant are $\delta\left[\mu\left[q-R_{0}\right]-\Pi_{d}^{2 E}\right]=\delta\left[\mu\left[q-R_{0}\right]-\mu(\bar{s}-2 \underline{s})^{2} / 9(\bar{s}-\underline{s})\right]$. Bank $A$ cannot guarantee itself a positive profit since it is optimal not to enter $B$ 's market in the second period. Therefore, it will not price lower in the first period than $R_{0} / \mu-\Pi_{d}^{2 I}=$ $R_{0} / \mu-\delta\left[(2 \bar{s}-\underline{s})^{2} / 9(\bar{s}-\underline{s})\right]$. That is, bank $A$ is willing to price up to the point where it loses up front the second-period incumbency profits. However, $A$ can drive $B$ out of the first-period market and still make positive profits. The intuition is that it offers its first-period borrowers the option to switch to bank $B$ in the second period in the event the borrowers' switching costs are low. Bank $B$ will not undercut bank $A$ 's offer since this would yield lower profits than entering in the second period. Remark that $R_{A}^{1}>R_{0} / \mu-\delta(\bar{s}+\underline{s}) / 3>R_{0} / \mu-\delta\left[(2 \bar{s}-\underline{s})^{2} / 9(\bar{s}-\underline{s})\right]$. The equilibrium profits become

$$
\begin{aligned}
\Pi_{A} & =\frac{\delta \mu(\bar{s}-2 \underline{s})^{2}}{6(\bar{s}-\underline{s})}>\Pi_{d}^{A} \\
\Pi_{B} & =\delta \Pi_{d}^{2 E} .
\end{aligned}
$$


Remark that $A$ 's profits are higher than when entering a market with information. Bank $A$ obtains a positive profit since bank $B$ does not want to price too aggressively and borrowers have a higher willingness to pay for bank $A$. The expected cost of switching equals $E\left(s \mid s<s^{*}\right)=(\bar{s}+4 \underline{s}) / 6$ since when $k=1$, we have that $\alpha=(2 \bar{s}-\underline{s}) / 3(\bar{s}-\underline{s})$.

\section{$5 \quad$ Equilibrium information disclosure}

In this section, we endogenize information disclosure decisions taken by banks. Our results are summarized in the following proposition:

Proposition 6 Incumbent banks strategically lower future barriers to entry by commiting to disclose information about their borrowers' characteristics.

The proof of the proposition is contained in the discussion below.

\subsection{Low asymmetric information}

Consider first the case where adverse selection is low, or $\mu \geq \mu^{*}$. Figure 2 summarizes the relevant bank payoffs. When both banks disclose their information $(I, I)$, their profits amount to $\delta \Pi_{d}^{2 E}$ as shown in Proposition 1. Without information disclosure $(N, N)$ both banks earn $\delta \Pi_{n}^{2 E}$ as shown in Proposition 2. Finally, Proposition 4 presents the results when only one bank discloses its information $(I, N$ or $N, I)$. Profits amount to $\delta \Pi_{d}^{2 E}-(1-\mu) b$ for the bank disclosing information while the bank not disclosing information receives a payoff equal to $\delta \Pi_{d}^{2 E}$. Information disclosure is weakly dominant for both players. ${ }^{13}$ Both banks are better off committing to provide information. Disclosing information is a weakly dominant strategy: whatever the strategy of the rival bank, a bank is never worse off providing information. This happens since $b<R_{0}$. The unique subgame perfect Nash equilibrium then becomes $(I, I)$. Thus, banks relax competition by providing information. Entry would take place independent of information. Providing information to the competitor improves the competitor's outside option and clearly relaxes competition.

\footnotetext{
${ }^{13}$ Information disclosure is strictly dominant when the cost of accessing the information is larger than the cost of disclosing.
} 


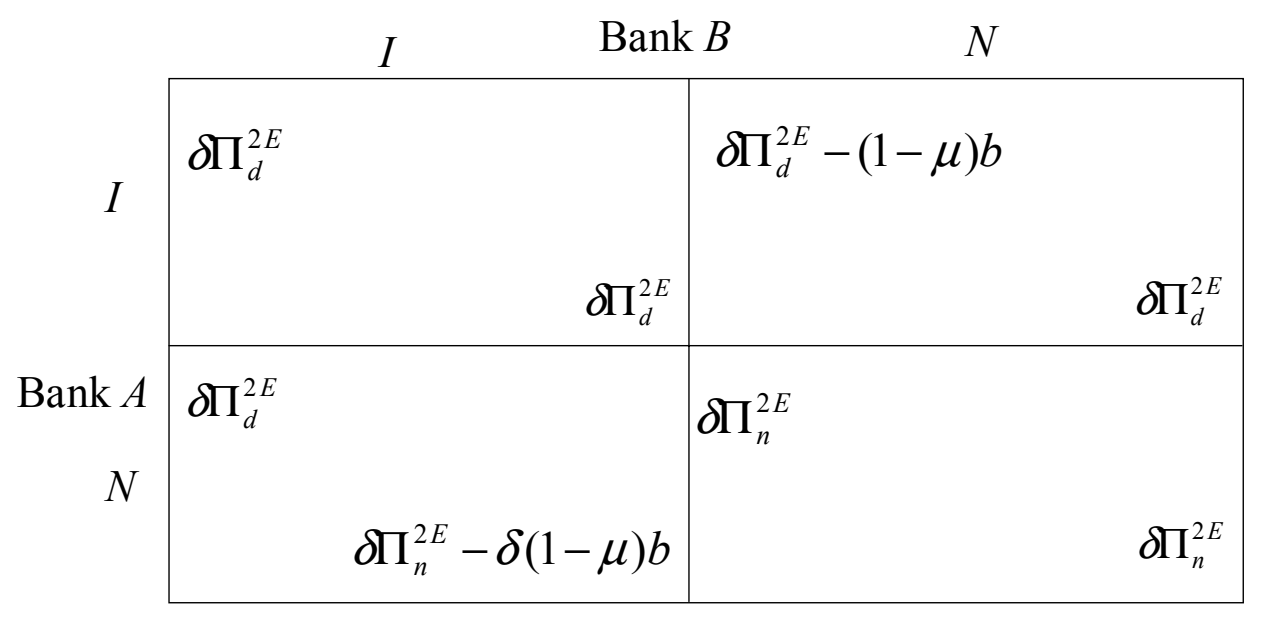

Figure 2: Profits with and without information disclosure when $\mu \geq \mu^{*}$.

\subsection{Substantial asymmetric information}

We analyze the case where a priori asymmetric information is substantial $\left(\mu<\mu^{*}\right)$. The relevant payoffs are summarized in Figure 3.

It is a weakly dominant strategy for every bank to provide information. The reason is that profits become zero in case banks do not offer information: second-period rents are entirely competed away in the first period. Thus, even with substantial asymmetric information, banks have incentives to unilaterally provide information to competitors. This improves the outside option of the rival bank and reduces overall competition.

\section{Discussion}

The model presented assumes that high-ability borrowers always execute successful projects. Information disclosure about project outcomes or borrower types then coincide. "Partial" information disclosure, i.e. disclosure about project outcomes only, differs from disclosure about borrower types when the high ability's success probability is less than one. With partial information disclosure, unsuccessful high-ability and low-ability borrowers are pooled together. Our results remain robust even when banks would be able to opt for "partial" information disclosure. Thus banks want to commit to disclose information about borrower types. The intuition is that borrowers in the first period have a higher 


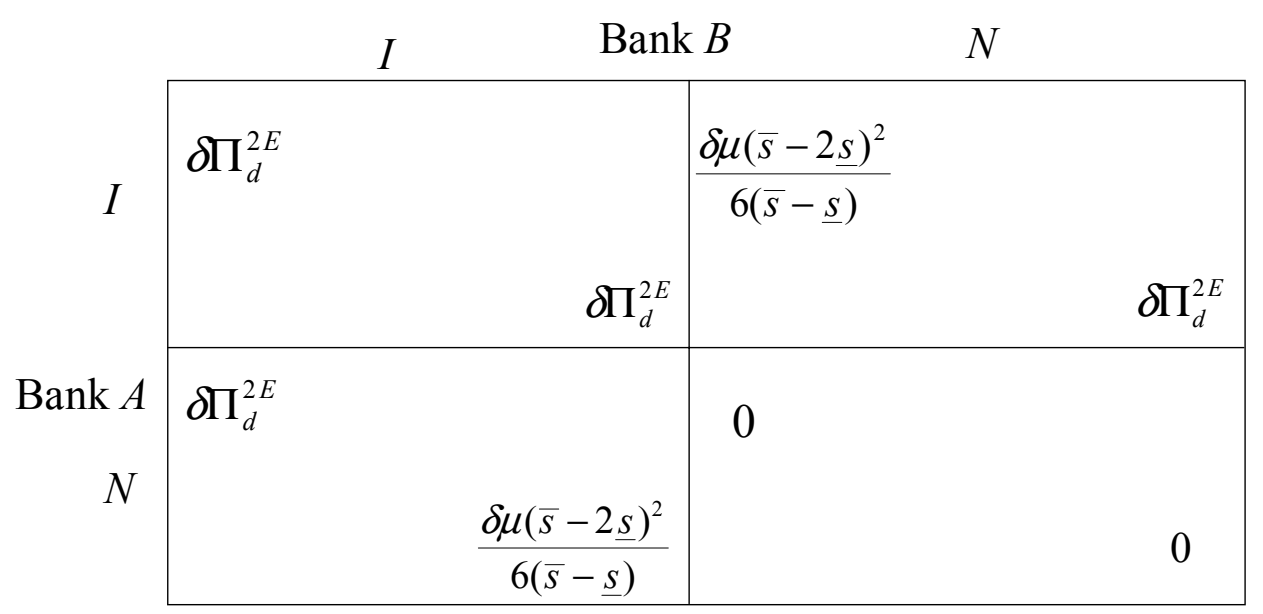

Figure 3: Profits with and without information disclosure when $\mu<\mu^{*}$.

willingness to pay for a bank committing to disclose its type. This result stands in contrast to Padilla and Pagano (2001) where sharing infromation about borrower types may reduce borrowers' incentives to perform.

We discussed unilateral information disclosure by banks. Banks however often $m u$ tually agree to exchange information, that is "share" information. Banks may decide whether to share information or not before competition in the loan market takes place. In practice, we observe voluntary and regulated information sharing among banks through credit bureaus and private credit registers (see Jappelli and Pagano (2000) for an overview). Our results also show that banks unilaterally commit to disclose information independently of their market share. Thus, it is as if information sharing among banks occurs. Actually information sharing only reinforces our results since then a bank anticipates to receive its rival's borrower information.

We started from sufficient heterogeneity in switching costs to allow for profitable entry. Even absent asymmetric information, profitable second-period entry is not possible when heterogeneity in switching costs is less substantially $(2 \underline{s}>\bar{s})$. The second-period incumbent bank would optimally set a second-period limit interest rate to retain all its high-ability borrowers (see e.g. Padilla and Pagano (2000)). This leaves zero profits for the entrant in the second period. Then information display does not affect future barriers to entry. Banks become indifferent between information disclosure or not.

Banks could consider to offer type contingent long term contracts to borrowers. It 
is clear that low-ability borrowers will be denied a loan in the second period. Ex ante, however, all or none of the borrowers would choose for the long term contract since they have similar expectations about their switching cost. Offering long term contracts that are chosen by borrowers relaxes second-period competition as borrowers are locked in into the long term contract (see Aghion and Bolton (1987)). However, this sharpens first-period competition as a bank only obtains profits when it is incumbent in the second period. Therefore, short term contracts relax overall competition and arrive endogenously in our setting.

Our setting only considers adverse selection problems. Information disclosure may also arise to curb moral hazard problems (see e.g. Padilla and Pagano (1997, 2000)). In that setting, banks may commit to share some information to induce borrowers to work hard. Adding a stage in which borrowers can influence their repayment probability may affect our results. We have shown that information disclosure relaxes competition. This introduces moral hazard problems: borrowers have less incentives to work hard. Committing not to disclose information may then induce borrowers to work harder at the cost of introducing harsher competition.

Borrower switching and low-ability borrowers obtaining loans drives welfare in our model. Information disclosure minimizes loans to low-ability borrowers but induces maximal switching. Welfare maximizing information disclosure hinges on the degree of asymmetric information. No information disclosure is optimal with substantial asymmetric information $\left(\mu<\mu^{*}\right)$. No second-period entry takes place. Therefore high-ability borrowers do not switch and low-ability borrowers do not obtain a second-period loan. The welfare maximizing solution endogenously arrives with low asymmetric information $\left(\mu \geq \mu^{*}\right)$. Entry takes place regardless of information disclosure. low-ability borrowers do not obtain a second-period loan with information disclosure.

Our model assumed borrowers learn their type and switching cost through lending. An alternative assumption would be that borrowers know their type and/or switching cost before accepting offers from banks. Borrowers that are informed about their type would not alter our results as long as they split in a similar way as high-ability borrowers among banks. low-ability borrowers understand the objectives of high-ability borrowers: they optimally hide behind high-ability borrowers to obtain a loan in the first period. Our results thus remain robust since again endogenous information disclosure reveals 
borrowers type in the second period. Borrowers may be informed before contracting about their learning switching costs. This complicates our analysis since then borrowers respond differently to interest rate changes depending on the magnitude of their switching costs.

We discuss a duopoly situation but admittedly this is a simplifying assumption. In reality we have more than two banks competing to attract borrowers. Our results qualitatively continue to hold as long as there is some form of imperfect competition between all other banks in the second period. This imperfect competition guarantees that committing to information disclosure relaxes future barriers to entry without all profits being competed away among entrants. When entrants are perfect substitutes in the second period, committing to disclose information does not affect the profits of entrants in the second period. This would produce perfect competition and the idea of relaxing competition through information disclosure would inevitably disappear.

Banks credibly commit to disclose information about borrowers through writing enforceable contracts with entrepreneurs or providing information to the rival bank. These contracts are renegotiation proof since the entrepreneurs want to enforce the contract. Banks however may want to revise the contract as they may want to informationally holdup the entrepreneur when asymmetric information is substantial. This could be captured by breach of contract. If breach of contract is possible, borrowers would rationally foresee this. Therefore the borrowers' willingness to pay for a bank committing to disclose information would decrease. Nevertheless, borrowers still prefer a bank committing to disclose information expecting breach of contract to one not disclosing information.

\section{Conclusion}

This paper shows that firms may soften overall competition by lowering future barriers to entry. In this way, firms invite entry into their incumbent market relaxing first-period competition. We provide an application of this more general result by looking at strategic information display in the banking industry. Bank-firm interaction provides a bank with an informational advantage about its borrowers. In the absence of entry, borrowers encounter an informational hold-up problem once a relationship is established. Moreover, with entry, borrowers may face learning switching costs in the action of visiting a bank. 
An incumbent bank therefore may prefer to price not too aggressively to milk some of its previous borrowers. Our results reveal that banks commit to provide information to competitors and give away their informational advantage. This action occurs for strategic reasons: providing information invites entry and augments the rival's secondperiod profits. The increase in the rival's second-period profits however dampens its incentives to win first-period competition and lure borrowers. In sum we have shown that information disclosure relaxes overall price competition. Our result also shows that competition in markets with sufficient heterogeneity in switching costs is relaxed even when taking into account first-period competition.

A bank strategically curbs the informational hold-up problem by committing to disclose information to competitors. Information disclosure increases the borrowers' firstperiod willingness to pay: borrowers anticipate the absence of the informational hold-up. The informational hold-up problem is however substituted by a switching cost hold-up problem: borrowers prefer the incumbent bank due to learning switching costs. Our model therefore rationalizes why in so many countries communication of information takes place.

Our results have important implications for financial integration and competition. This model suggests that banks may be willing to stimulate financial integration by committing to disclose information about borrowers. Banks may suffer in the short run since they are giving away informational rents. Ex ante however, overall banking competition may be relaxed.

\section{References}

Aghion, Philippe and Bolton, Patrick, Contracts as a Barrier to Entry, American Economic Review, 77, 1987, 388-401.

Bester, Helmut, Bertrand Equilibrium in a Differentiated Duopoly, International Economic Review 33, 1992, 433-448.

Bouckaert, Jan and Degryse, Hans, Entry and Strategic Information Display in Credit Markets, 2001, mimeo.

Dell'Ariccia, Giovanni, Friedman, Ezra, and Marquez, Robert, 1999, "Adverse Selection as a Barrier to Entry in the Banking Industry," RAND Journal of Eco- 
nomics, 30, Autumn, 515-34.

Gehrig, Thomas and Stenbacka, Rune, "Information Sharing in Banking: A Collusive Device?," 2001, CEPR Discussion Paper № 2911.

Jappelli, Tullio and Pagano, Marco, "Information Sharing in Credit Markets: A Survey", CSEF Working Paper N 36, 2000, University of Salerno.

Kallberg, Jarl G. and Udell, Gregory F., 2001, "The Value of Private Sector Credit Information Sharing: The U.S. Case, Kelley School of Business Indiana Univerity Working Paper.

Klemperer, Paul, Entry Deterrence in Markets with Switching Costs, The Economic Journal, 1987, 97 (Conference 87), 99-117.

Klemperer, Paul, "Competition when Consumers have Switching Costs: An Overview with Applications to Industrial Organization, Macroeconomics, and International Trade," Review of Economic Studies, October 1995, 62, 515-539.

Nilssen, Tore, Two kinds of switching costs, RAND Journal of Economics, 1992, 23, Winter, 579-589.

Nilssen, Tore, "Consumer Lock-In with Asymmetric Information," International Journal of Industrial Organization, 2000, 18, 641-666.

Padilla, Jorge A. and Pagano, Marco, "Endogenous Communication Among Lenders and Entrepreneurial Incentives," Review of Financial Studies, January 1997, 10, $205-236$.

Padilla, Jorge A. and Pagano, Marco, "Sharing Default Information as a Borrower Discipline Device," European Economic Review, December 2000, 44, 1951-1980.

Pagano, Marco, 2002, "Measuring financial integration," paper presented at launching workshop of ECB-CFS Research Network on "Capital Markets and Financial Integration in Europe.

Pagano, Marco and Jappelli, Tullio, "Information Sharing in Credit Markets," Journal of Finance, December 1993, 48, 1693-1718.

Rajan, Raghuram, "Insiders and Outsiders: The Choice between Informed and Arm's-length debt," Journal of Finance, September 1992, 47, 1367-1400.

Rønde, Thomas, Trade Secrets and Information Sharing, Journal of Economics and Management Strategy, 2001, 10, 3, 391-417.

Sharpe, Stephen A., "Asymmetric Information, Bank Lending, and Implicit Con- 
tracts: A Stylized Model of Customer Relationships," Journal of Finance, 1990, 45, 1069-1087.

Tirole, Jean, The Theory of Industrial Organization, 1988, MIT Press.

von Thadden, Ernst-Ludwig, "Asymmetric Information, Bank Lending and Implicit Contracts : The Winner's Curse," 2001, forthcoming in Journal of Finance.

Vives, Xavier, "Competition in the changing world of banking," Oxford Review of Economic Policy, 2001, 17, 535-547. 